\title{
Maternal intake of trans-unsaturated or interesterified fatty acids during pregnancy and lactation modifies mitochondrial bioenergetics in the liver of adult offspring in mice
}

\author{
Patricia C. de Velasco ${ }^{1 *} \dagger$, Gustavo Chicaybam ${ }^{2} \dagger$, Dionizio M. Ramos-Filho ${ }^{2}$, Raísa M. A. R. dos Santos ${ }^{1}$, \\ Caroline Mairink ${ }^{1}$, Fátima L. C. Sardinha ${ }^{1}$, Tatiana El-Bacha ${ }^{1}$, Antonio Galina ${ }^{2}$ and \\ Maria das Graças Tavares-do-Carmo ${ }^{1}$ \\ ${ }^{1}$ Laboratório de Bioquímica Nutricional, Centro de Ciências da Saúde, Instituto de Nutrição Josué de Castro, Universidade \\ Federal do Rio de Janeiro, Rio de Janeiro, 21941902, Brazil \\ ${ }^{2}$ Laboratório de Bioenergética e Fisiologia Mitocondrial, Centro de Ciências da Saúde, Instituto de Bioquímica Médica \\ Leopoldo de Meis, Universidade Federal do Rio de Janeiro, Rio de Janeiro, 21941599, Brazil
}

(Submitted 29 November 2016 - Final revision received 17 May 2017 - Accepted 21 June 2017)

\section{Abstract}

The quality of dietary lipids in the maternal diet can programme the offspring to diseases in later life. We investigated whether the maternal intake of palm oil or interesterified fat, substitutes for trans-unsaturated fatty acids (FA), induces metabolic changes in the adult offspring. During pregnancy and lactation, $\mathrm{C} 57 \mathrm{BL} / 6$ female mice received normolipidic diets containing partially hydrogenated vegetable fat rich in trans-unsaturated fatty acids (TG), palm oil (PG), interesterified fat (IG) or soyabean oil (CG). After weaning, male offspring from all groups received the control diet until day 110. Plasma glucose and TAG and liver FA profiles were ascertained. Liver mitochondrial function was accessed with high-resolution respirometry by measuring $\mathrm{VO}_{2}$, fluorimetry for detection of hydrogen peroxide $\left(\mathrm{H}_{2} \mathrm{O}_{2}\right)$ production and mitochondrial $\mathrm{Ca}^{2+}$ uptake. The results showed that the IG offspring presented a $20 \%$ increase in plasma glucose and both the IG and TG offspring presented a 2- and 1.9-fold increase in TAG, respectively, when compared with CG offspring. Liver MUFA and PUFA contents decreased in the TG and IG offspring when compared with CG offspring. Liver MUFA content also decreased in the PG offspring. These modifications in FA composition possibly affected liver mitochondrial function, as respiration was impaired in the $\mathrm{TG}_{\mathrm{G}}$ offspring and $\mathrm{H}_{2} \mathrm{O}_{2}$ production was higher in the IG offspring. In addition, mitochondrial $\mathrm{Ca}^{2+}$ retention capacity was reduced by approximately 40 and $55 \%$ in the TG and IG offspring, respectively. In conclusion, maternal consumption of trans-unsaturated and interesterified fat affected offspring health by compromising mitochondrial bioenergetics and lipid metabolism in the liver.

Key words: Dietary lipids: Metabolic programming: Liver mitochondria: trans-fatty acids: Interesterified fat

Fetal programming is a phenomenon characterised by adaptive responses of the fetus to specific environmental conditions (e.g. nutrition) during early life stages, which may alter gene expression and permanently affect the structure and function of several organs and tissues, most likely influencing the individual's susceptibility to develop metabolic disorders over a lifetime, such as type 2 diabetes, CVD, obesity and hypertension ${ }^{(1,2,3)}$.

Dietary fatty acids (FA) are one of the nutritional environmental factors that are capable of inducing changes in development and fetal programming ${ }^{(4,5,6)}$. As integral components of the phospholipid structure of biological membranes, FA play pivotal roles in cell function and tissue growth, modulation of intercellular and intracellular communication, control of gene expression and epigenetic regulation ${ }^{(7,8,9)}$.

Studies on trans-unsaturated fatty acids (TFA), present in partially hydrogenated vegetable oil, have shown an association between oxidative stress, elevated pro-inflammatory cytokines, insulin resistance and metabolic programming ${ }^{(6,10)}$, indicating that the consumption of these FA during pregnancy and lactation should be reduced ${ }^{(11)}$. The use of several industrialised food products rich in TFA has led many countries to regulate the use of partially hydrogenated vegetable fat in processed foods and search for alternative sources to maintain product consistency and quality. Palm oil (PO), a natural vegetal source of saturated fat,

Abbreviations: CG, control group; CL, cardiolipin; ETS, electron transfer system; FA, fatty acids; FCCP, carbonyl cyanide-4-(trifluoromethoxy) phenylhydrazone; $\mathrm{H}_{2} \mathrm{O}_{2}$, hydrogen peroxide; IG, interesterified fat group; IF, interesterified fat; LA, linoleic acid; MPTP, mitochondrial permeability transition pore; PG, palm oil group; PO, palm oil; ROS; reactive $\mathrm{O}_{2}$ species; SUCC, succinate; TG, trans-fat group; TFA, trans-unsaturated fatty acids.

* Corresponding author: Dr P. C. de Velasco, email patriciac.velasco@gmail.com

$\dagger$ These authors contributed equally to this work. 
has been used in particular because of its texture and stability $^{(12,13)}$. Another alternative is the use of interesterified fat (IF), which results in a modification of the position of the FA in the glycerol molecule, forming a new $\mathrm{TAG}^{(14)}$. However, such substitution has been conducted without further studies on the effects of these types of fats on the metabolism and on long-term health.

Recently, our group demonstrated, in a fetal programming model for mice, that the maternal intake of PO or IF may predispose the adult offspring to obesity, promoting the accumulation of total body fat and increasing adipocyte number and area ${ }^{(15)}$. In addition, Misan et al. ${ }^{(16)}$ showed that the maternal intake of TFA, PO or IF can trigger the initial steps of inflammatory pathways in the brain of the offspring in adult life, increasing Toll-like receptor 4 signalling and leucocyteendothelial interactions in cerebral microcirculation. These results provide consistent evidence that the type of dietary FA consumed by dams during the perinatal period is an important dietary/environmental factor involved in the metabolic disturbances observed in later life.

Although the molecular mechanisms by which maternal lipid intake affects long-term health of the offspring are still not completely understood, it was demonstrated that alterations in mitochondrial function in different tissues play important roles in metabolic disturbances ${ }^{(17)}$. FA are also of crucial importance in the composition of mitochondrial membranes, affecting mitochondria structure and function. The saturation of FA could generate disturbances in mitochondrial membrane fluidity, modifications in respiratory functions and the organisation of chain complexes, which may result in an increased production of reactive $\mathrm{O}_{2}$ species (ROS) ${ }^{(18)}$ or mitochondrial permeability transition pore (MPTP) in which necrotic cell death may lead to pro-inflammatory states ${ }^{(19,20)}$.

High-fat ${ }^{(21)}$ and high-lard diets ${ }^{(22)}$ impaired mitochondrial functions by altering the lipid composition of liver mitochondria in mice. In addition, mice fed a high-fat diet presented a decrease in respiration coupled to ATP synthesis and a decrease in ATP content in liver mitochondria ${ }^{(17,23)}$. These effects seem to be mediated by an increase in ROS production. Moreover, altered mitochondrial fission and fusion ${ }^{(24)}$ and decreased FA oxidation $^{(25)}$ are some possible mechanisms related to highfat-diet-induced metabolic programming.

To the best of our knowledge, no studies have examined the effects of dietary palm and IF - products used to replace partially hydrogenated fats in processed foods - on mitochondrial bioenergetics, particularly during the critical developmental period of the liver. Thus, the purpose of the present study was to investigate whether normolipidic diets containing TFA-rich hydrogenated fat, or its industrial substitute lipid sources, during pregnancy and lactation can predispose the adult offspring to metabolic changes and mitochondrial dysfunction, by evaluating liver bioenergetics, FA profiles and parameters of oxidative stress.

\section{Methods}

\section{Animals}

C57BL/6 mice (20-25g) were obtained from the animal breeding unit at the Institute of Nutrition of the Federal
University of Rio de Janeiro (UFRJ) and were maintained under humidity- and temperature-controlled $\left(24 \pm 1{ }^{\circ} \mathrm{C}\right)$ conditions with a $12 \mathrm{~h}$ light $-12 \mathrm{~h}$ dark cycle and ad libitum access to water and diets.

Experimental procedures followed the national guidelines for Animal Experimentation, and The Experimental Research Committee of the Federal University of Rio de Janeiro (Rio de Janeiro, Brazil) approved all the procedures involving animals, under the reference no. INJC011 (CEUA/UFRJ).

\section{Experimental design}

Female mice, 3-month-old, were left overnight to mate, and copulation was verified by the presence of sperm on the vaginal smears, as previously described by Misan et al. ${ }^{(16)}$. On the 1 st day of pregnancy, dams were isolated in individual cages and randomly divided into four groups. The control group (CG; 6-8/ group) received a diet containing $7 \%$ of soyabean oil. The partially hydrogenated vegetable oil rich in trans-fatty acid group (TG; 6-8/group) received $6 \%$ partially hydrogenated vegetable oil plus $1 \%$ soyabean oil. The palm oil group (PG; 6-8/group) received 5\% PO plus $2 \%$ soyabean oil, and the interesterified fat group (IG; 6-8/group) received 5\% IF plus $2 \%$ soyabean oil. Dams were fed their respective group diets throughout pregnancy and lactation. On the day of birth, considered day 0 of lactation, each mother was kept with her six to eight pups. At postnatal day 21, litters were weaned and male pups from each group had their diet changed to the control diet (soyabean oil) until the 110th day of life (Fig. 1).

\section{Diets}

All diets were isoenergetic (providing $17 \cdot 2 \mathrm{~kJ} / \mathrm{g}$ of dry diet) and differed from each other only in the nature of lipid source. The diet compositions followed the recommendations of the American Institute of Nutrition (AIN-93) ${ }^{(26)}$, as described in Misan et $a l .{ }^{(16)}$. The composition of the experimental diets is shown in Table 1.

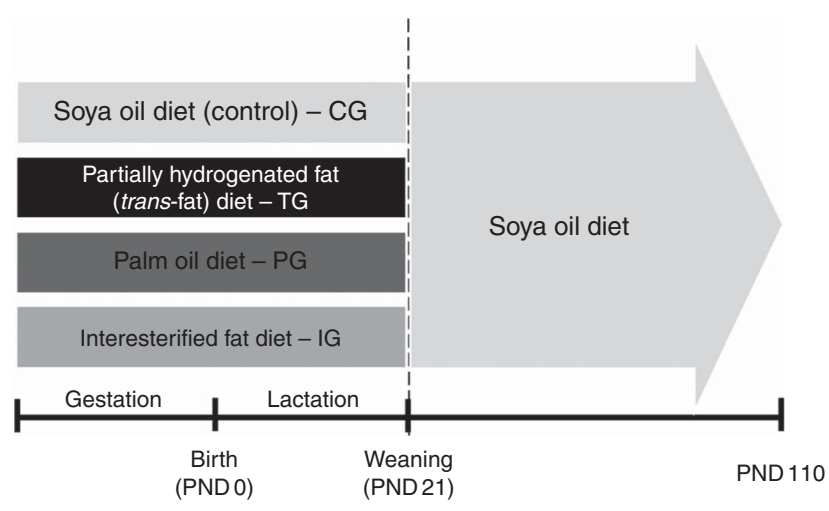

Fig. 1. Summary of experimental design. On the 1st day of pregnancy, dams were divided in groups and received diets with different sources of fat: soyabean oil (control diet - CG), partially hydrogenated vegetable oil rich in trans-fatty acids (TG), palm oil (PG) and interesterified fat (IG). Dams were fed each diet during pregnancy, and after delivery litters received diets through lactation. After weaning (postnatal day 21 - PND21), litters from all experimental groups were fed control diet until PND110 (adulthood), when analyses were performed. 
Table 1. Composition of diets $(\mathrm{g} / \mathrm{kg}$ dry diet)

\begin{tabular}{|c|c|c|c|c|}
\hline & so & PHVF & $\mathrm{PO}$ & IF \\
\hline $\mathrm{SO}(\mathrm{ml})$ & 70 & 10 & 20 & 20 \\
\hline $\begin{array}{l}\text { Partially } \\
\text { hydrogenated fat }\end{array}$ & - & 60 & - & - \\
\hline IF & - & - & - & 50 \\
\hline PO & - & - & 50 & - \\
\hline Starch & 397.49 & 397.49 & 397.49 & 397.49 \\
\hline Casein & 200 & 200 & 200 & 200 \\
\hline Dextrin & 132 & 132 & 132 & 132 \\
\hline Sugar & 100 & 100 & 100 & 100 \\
\hline Cellulose & 50 & 50 & 50 & 50 \\
\hline$\beta$-Choline & 2.5 & 2.5 & 2.5 & 2.5 \\
\hline L-Cystine & 3 & 3 & 3 & 3 \\
\hline $\begin{array}{l}\text { Mix of minerals } \\
\mathrm{G}^{*} \text { and } \mathrm{M} \dagger\end{array}$ & 35 & 35 & 35 & 35 \\
\hline Mix of vitamins $\ddagger$ & 10 & 10 & 10 & 10 \\
\hline BHT & 0.014 & 0.014 & 0.014 & 0.014 \\
\hline Energy value (kJ/kg) & $16526 \cdot 8$ & $16526 \cdot 8$ & $16526 \cdot 8$ & $16526 \cdot 8$ \\
\hline
\end{tabular}

SO, soyabean oil; PHVF, partially hydrogenated vegetable fat; PO, palm oil; IF, interesterified fat; $\mathrm{BHT}$, butylhydroquinone.

* Salt mix G (mg/kg diet) for growth, pregnancy and lactation periods: $\mathrm{Ca}, 5000.0 ; \mathrm{P}$ 1561.0; K, 3600.0; S, 300.0; Na, 1019.0; Cl, 1571.0; Mg, 507.0; Fe, 35.0; Zn, 30.0; $\mathrm{Mn}, 10.0 ; \mathrm{Cu}, 6.0$; I, 0.2; Mo, 0.15; Se, 0.15; Si, 5.0; Cr, 1.0; F, 1.0; Ni, 0.5; B, 0.5; Li, $0.1 ; \mathrm{V}, 0.1$

† Salt mix M (mg/kg diet) for maintenance periods: Ca, 5000.0; P, 1992.0; K, 3600.0; S, 300.0; Na, 1019.0; Cl, 1571.0; Mg, 507.0; Fe, 35.0; Zn, 30.0; Mn, 10.0; Cu, 6.0; I 0.2; Mo, 0.15; Se, 0.15; Si, 5.0; Cr, 1.0; F, 1.0; Ni, 0.5; B, 0.5; Li, 0.1; V, 0.1.

‡ Vitamin mix (mg/kg diet): retinyl palmitate, 2.4; cholecalciferol, 0.025; menadione sodium bisulfite, 0.8 ; biotin, 0.22 ; cyanocobalamin, 0.01 ; riboflavin, 6.6 ; thiamin hydrochloride, 6.6; tocopheryl acetate, 100.

Table 2. Fatty acid profile (\% of total) of the experimental diets (Mean values with their standard errors)

\begin{tabular}{|c|c|c|c|c|c|c|c|c|}
\hline & \multicolumn{2}{|c|}{ SO } & \multicolumn{2}{|c|}{ PHVF } & \multicolumn{2}{|c|}{ PO } & \multicolumn{2}{|c|}{ IF } \\
\hline & Mean & SEM & Mean & SEM & Mean & SEM & Mean & SEM \\
\hline $16: 0$ & 11.6 & 0.4 & $16 \cdot 80$ & 0.06 & 34.8 & 2.4 & $23 \cdot 3$ & 8.8 \\
\hline $18: 0$ & 3.7 & 0.2 & $20 \cdot 81$ & 0.74 & $5 \cdot 0$ & 0.1 & $17 \cdot 8$ & $6 \cdot 0$ \\
\hline$\Sigma$ SFA & $16 \cdot 8$ & 0.7 & 41.43 & 0.68 & $42 \cdot 2$ & 2.4 & 49.5 & 0.5 \\
\hline $18: 1(n-9)$ & $24 \cdot 1$ & 0.2 & 16.95 & 0 & 38.2 & $2 \cdot 7$ & $20 \cdot 7$ & 1 \\
\hline$\Sigma$ MUFA & $26 \cdot 5$ & 0.2 & $23 \cdot 12$ & 0.14 & 39.5 & $2 \cdot 6$ & $22 \cdot 4$ & 0.7 \\
\hline $18: 2(n-6)$ & $50 \cdot 8$ & 0.4 & $10 \cdot 46$ & 0.02 & $17 \cdot 0$ & 2.9 & 25.5 & 0.4 \\
\hline $18: 3(n-3)$ & 5.4 & 0.3 & 0.95 & 0.02 & 1.0 & 0.4 & 1.9 & 0.4 \\
\hline ¿PUFA & $56 \cdot 2$ & 0.2 & 11.41 & 0.01 & $18 \cdot 1$ & 3.3 & $27 \cdot 3$ & 0.8 \\
\hline$\Sigma T F A$ & 0.3 & 0.07 & 22.9 & $1 \cdot 1$ & 0.3 & 0.0 & 1.6 & 0.5 \\
\hline
\end{tabular}

SO, soyabean oil; PHVF, partially hydrogenated vegetable fat; PO, palm oil; IF, interesterified fat.

Soyabean oil (ml) was added to each diet to adjust the essential FA requirements in each diet. Diets were freshly prepared every $3 \mathrm{~d}$ as pellets, gassed with $\mathrm{N}_{2}$ and stored at $-20^{\circ} \mathrm{C}$ until use. All fats used in the diets were donated by INDÚSTRIA TRIÂNGULO ALIMENTOS LTDA. According to the company, soyabean oil is used for the formulation of partially hydrogenated vegetable oil. Four different types of lipids, palm kernel oil (2.5\%), palm stearin ( $45 \%)$, soyabean oil ( $45 \%)$ and fully hydrogenated fat $(7.5 \%)$, were used to prepare the IF.

The FA composition of dietary fats was determined by GC and is presented in Table 2. The methylated FA were identified based on a comparison with the relative retention time of the standard peaks. The characterisation of each FA was performed by area normalisation, expressed as a percentage of the total FA (mean and SEm/ $n$ 6). The trans-fat experimental diet had increased levels of trans-fatty acids when compared with all the diets offered. The PO, trans-fat and IF diets had more SFA when compared with the control diet. In addition, all experimental diets had lower levels of total PUFA, mostly from the $n-3$ and $n-6$ families $^{(15)}$.

\section{Determination of plasma glucose and TAG}

Blood was obtained from male mice, after an 8-h fast, anaesthetised with ketamine and xilazine by cardiac puncturing. Blood was then distributed in tubes $(1 \mathrm{ml})$ with EDTA and centrifuged at $3000 \mathrm{rpm}$ for $15 \mathrm{~min}$ at $4^{\circ} \mathrm{C}$ and the plasma was collected and stored at $-80^{\circ} \mathrm{C}$. For determining the plasma glucose and TAG levels, we used enzymatic colorimetric kits (BIOCLIN). All samples $(10 \mu \mathrm{l})$ were well homogenised with the specific reagents, put in a water bath at $37^{\circ} \mathrm{C}$ for $10 \mathrm{~min}$ and then placed into microplates for absorbance reading. The absorbance of samples and standard was performed at $500 \mathrm{~nm}$. The plasma glucose and TAG were calculated by multiplying the sample absorbance per 100 and dividing by standard absorbance. The data were expressed in $\mathrm{mmol} / \mathrm{l}$.

\section{Determination of liver fatty acids profile}

The relative content of FA from the total lipids from male offspring livers was determined by GC, using an Agilent Technologies 7890A GC System, equipped with a flame ionisation detector, coupled to EZChrom Elite CDS software (Agilent Technologies Inc.). The lipid extraction, saponification and methylation of FA were performed by direct methylation, according to the official method of the American Oil Chemists' Society, and implemented in the laboratory. The methyl esters were separated using a fused silica capillary column, SP-2560 bis-cyanopropylpolysiloxane (Supelco Inc.) with an internal diameter of $100 \mathrm{~m} \times 0.25 \mathrm{~mm} \times 0.2 \mu \mathrm{m}$, whose programming column temperature was set to $100^{\circ} \mathrm{C}$ with a gradual increase of $3^{\circ} \mathrm{C} / \mathrm{min}$ until it reached $140^{\circ} \mathrm{C}$. The temperature increased at a rate of $0.5^{\circ} \mathrm{C} / \mathrm{min}$ until it reached $170^{\circ} \mathrm{C}$, and then $3.2^{\circ} \mathrm{C} / \mathrm{min}$ until it reached $220^{\circ} \mathrm{C}$ and was then kept at this temperature for $35 \mathrm{~min}$. The injector and detector temperatures were $250^{\circ} \mathrm{C}$. The flow of gases (Linde Gases) was $0.75 \mathrm{ml} / \mathrm{min}$ for the carrier gas $\left(\mathrm{H}_{2}\right), 25 \mathrm{ml} / \mathrm{min}$ for the auxiliary gas $\left(\mathrm{N}_{2}\right)$ and $30 \mathrm{ml} / \mathrm{min}$ and $400 \mathrm{ml} / \mathrm{min}$ for $\mathrm{H}_{2}$ and synthetic air to the flame, respectively. The splitter reason (split) was $1 / 100$. The injections were performed with an automatic injector and the volume was $1 \mu \mathrm{l}$.

FA methyl esters were identified on the basis of a comparison of the relative retention time of the peaks of standards from $\mathrm{Nu}-$ Chek Prep Inc., a blend of methyl esters 463, and the quantification of each FA was carried out by normalisation of areas, expressed as a percentage of total FA.

\section{Isolation of mitochondria}

Animal and liver weights were collected. After that, liver samples were placed on ice during the procedures. About $1 \mathrm{~g}$ of tissue was placed in an isolation buffer that contained mannitol $225 \mathrm{~mm}$, sucrose $75 \mathrm{~mm}$, EGTA (ethylene glycol-bis(2-aminoethyl-

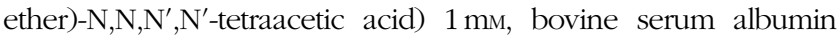


(BSA) $0 \cdot 1 \%$ and HEPES $10 \mathrm{~mm}(\mathrm{pH} 7 \cdot 2)$ at $4^{\circ} \mathrm{C}$. The mitochondria from mouse livers were isolated by differential centrifugation with modifications ${ }^{(27,28)}$. Tissues were sliced and washed in the isolation buffer. After four washes, livers were homogenised by hand in a glass potter with a Teflon piston rotated for six cycles. The homogenates were centrifuged (Hitachi) at $200 \boldsymbol{g}$ for $5 \mathrm{~min}$. The supernatants were carefully separated and then centrifuged at $10000 \boldsymbol{g}$ for $8 \mathrm{~min}$. After that, the supernatants were discarded and the precipitants were resuspended in the isolation buffer and were considered as the mitochondrial fractions. Protein concentration was determined using BSA as a standard ${ }^{(29)}$ and the mitochondrial fractions ranged from 19 to $23 \mathrm{mg} / \mathrm{ml}$.

\section{$\mathrm{VO}_{2}$ measurements and mitochondrial bioenergetics parameters}

$\mathrm{VO}_{2}$ was measured with the polarography technique using high-resolution respirometry (Oxygraph-O2K; Oroboros Instruments $\left.{ }^{\circledR}\right)$. Measurements were performed in a chamber with controlled temperature $\left(37^{\circ} \mathrm{C} \pm 0.001^{\circ} \mathrm{C}\right)$ and the electrode was calibrated for $0-100 \%$ of saturation $(220 \mu \mathrm{M} \mathrm{O})$ and atmospheric pressure $(101.3 \mathrm{kPa})$. Mouse liver mitochondrial fractions $(0.5 \mathrm{mg} / \mathrm{ml})$ were incubated with $2.0 \mathrm{ml}$ of respiratory buffer MIR05 containing sucrose $110 \mathrm{~mm}$, EGTA $0.5 \mathrm{~mm}, \mathrm{MgCl}_{2}$ $3 \mathrm{~mm}$, MES $60 \mathrm{~mm}$, Taurine $20 \mathrm{~mm}, \mathrm{KH}_{2} \mathrm{PO}_{4} 10 \mathrm{~mm}$, HEPES $20 \mathrm{mM}$ and $\mathrm{BSA} 0 \cdot 1 \%(\mathrm{pH} 7 \cdot 2)$, under constant shaking ${ }^{(30)}$. $\mathrm{VO}_{2}$ rates were monitored according to the protocol described in Pesta \& Gnaiger with modifications ${ }^{(31)}$, using a sequential addition of substrates from complex I (pyruvate/malate/glutamate (PMG), 2 mм each) or complex II (succinate (SUCC) $2 \mathrm{~mm}$ ), followed by ADP $100 \mu \mathrm{m}$, ADP $1 \mathrm{~mm}$, oligomycin $2 \mu \mathrm{g} / \mathrm{ml}$, carbonyl cyanide4-(trifluoromethoxy) phenylhydrazone (FCCP) $0.25 \mu \mathrm{M}$, FCCP $0.25 \mu \mathrm{m}$, rotenone $0.5 \mu \mathrm{m}$ or malonate $5 \mathrm{~mm}$, and potassium cyanide (KCN) $2 \mathrm{~mm}$. Results were expressed in pmol $\mathrm{O}_{2} / \mathrm{mg}$ of protein $\times \mathrm{s}^{(32)}$.

\section{Citrate synthase enzyme activity}

Citrate synthase (CS) activity was measured in isolated liver mitochondria samples, as previously described, with minor modifications $^{(32,33)}$. The reaction medium contained $20 \mathrm{~mm}$ TRIS-HCl, pH 8, 0.3 mm 5,5'-dithio-bis (2-nitrobenzoic acid) (DTNB), 2 mм EDTA, $0 \cdot 3$ mm acetyl coenzyme A and $100 \mu \mathrm{g} / \mathrm{ml}$ protein. The medium was incubated for $5 \mathrm{~min}$ with continuous shaking at $37^{\circ} \mathrm{C}$ and the reaction was initiated with the addition of $5 \mathrm{~mm}$ oxaloacetate. The reactions were performed in a 96-well plate, and the results were read at $420 \mathrm{~nm}$ in a VictorPerkin Elmer plate reader. The specific activity was calculated based on a curve of CoA in the presence of $0.3 \mathrm{~mm}$ DTNB and was expressed as $\mu \mathrm{mol}$ citrate/min per $\mathrm{mg}$ protein.

\section{Hydrogen peroxide production in liver mitochondria}

Mitochondrial release of hydrogen peroxide $\left(\mathrm{H}_{2} \mathrm{O}_{2}\right)$ was determined using the Amplex Red ${ }^{\circledR}$ ( $N$-acetyl-3, 7-dihydroxyphenoxazine) oxidation method ${ }^{(34)}$. Liver mitochondrial fractions from mice $(0.5 \mathrm{mg}$ protein $/ \mathrm{ml})$ were incubated in the MIR05 (pH 7.2) buffer, supplemented with $5 \mu \mathrm{M}$ Amplex Red and 4 units/ml horseradish peroxidase. The fluorescence was monitored with a Spectrofluorimeter (Varian Cary Eclipse ${ }^{\circledR}$; Agilent Technologies) at 563-nm excitation (slit $5 \mathrm{~nm}$ ) and 587-nm emission wavelengths (slit $5 \mathrm{~nm}$ ) under constant shaking at $37^{\circ} \mathrm{C}^{(28,32)}$. The rate of mitochondrial $\mathrm{H}_{2} \mathrm{O}_{2}$ production was assessed through a standard curve with known amounts of $\mathrm{H}_{2} \mathrm{O}_{2}$. Results were expressed in pmol $\mathrm{H}_{2} \mathrm{O}_{2} / \mathrm{mg}$ of protein $\times$ min. The experiments were done with sequential addition of substrates from complex I (PMG, 2 mм each) or complex II (SUCC $2 \mathrm{~mm}$ ), followed by $0.5 \mathrm{mM}$ ADP, $2 \mu \mathrm{g} / \mathrm{ml}$ oligomycin, $0.5 \mu \mathrm{M}$ FCCP and $5 \mu \mathrm{m}$ antimycin A.

\section{Determination of electron leakage}

We estimated the fraction of electrons that leaked out of the respiratory chain by dividing the rate of $\mathrm{H}_{2} \mathrm{O}_{2}$ formation by the rate of $\mathrm{VO}_{2}{ }^{(32,35)}$. To calculate electron leakage, these measurements were expressed using the same units (pmol/ $\min \times \mathrm{mg}$ ) at the same respiratory state. The electron leakage related to a specific substrate was calculated as the ratio of $\mathrm{H}_{2} \mathrm{O}_{2}$ formed by a specific substrate (for example, SUCC) to $\mathrm{VO}_{2}$ with that substrate.

\section{Determination of calcium retention capacity}

The capacity to retain $\mathrm{Ca}^{2+}$ was determined using the method proposed by Wong et $a l .{ }^{(36)}$. Mitochondrial fractions of mouse liver were incubated in MIR05 buffer without EGTA ( $\mathrm{pH} 7.2$ ) at $37^{\circ} \mathrm{C}$, with the addition of Calcium Green $0 \cdot 2 \mu \mathrm{M}\left(\right.$ Invitrogen $\left.^{\circledR}\right)$, a fluorescent marker that indicates the presence of $\mathrm{Ca}^{2+}$ in the medium. After that, the respective substrates from Complex I and II were added, followed by successive additions of $30 \mu \mathrm{m}$ calcium chloride $\left(\mathrm{CaCl}_{2}\right)$. Experiments were conducted in a Spectrofluorometer (Varian Cary Eclipse ${ }^{\circledR}$ ) at 506-nm excitation (slit $10 \mathrm{~nm}$ ) and 532-nm emission (slit $10 \mathrm{~nm}$ ) wavelengths under constant shaking at $37^{\circ} \mathrm{C}$.

\section{Statistical analysis}

$\mathrm{VO}_{2}$ measurements were analysed using DatLab 5 software. The results of $\mathrm{H}_{2} \mathrm{O}_{2}$ production and $\mathrm{Ca}^{2+}$ retention capacity were analysed using Origin 8.0 software. For statistical analysis of the data obtained in each of the groups, we used GraphPad Prism 6.0 software, with which we performed an ANOVA. Values were expressed as means with their standard errors. To compare the average results obtained between groups, we applied post-test Newman-Keuls or Dunnett's tests for multiple comparisons, adopting a significance level of $P<0.05$, as a parameter for determining the differences between the groups. Sample size was calculated to provide $5 \%$ error and $95 \%$ confidence.

\section{Results}

Differences in total body weight, liver weight and plasma glucose and TAG levels in adult male mouse offspring

At $110 \mathrm{~d}$ of life, the groups did not present differences in absolute weight or in liver weight (Table 3). On the other hand, when we analysed the liver/body weight ratio, we observed increased ratios in the groups in which mothers were fed TG or IG diets. 
Table 3. Total body weight, liver weight and plasma glucose and TAG levels of male offspring at $110 \mathrm{~d}$ of life (Mean values with their standard errors, $n 7-8$ )

\begin{tabular}{|c|c|c|c|c|c|c|c|c|}
\hline & \multicolumn{2}{|c|}{ CG } & \multicolumn{2}{|c|}{ TG } & \multicolumn{2}{|c|}{$P G$} & \multicolumn{2}{|c|}{ IG } \\
\hline & Mean & SEM & Mean & SEM & Mean & SEM & Mean & SEM \\
\hline Body weight (g) & 29.08 & $1 \cdot 1$ & $27 \cdot 12$ & 0.6 & $27 \cdot 31$ & 0.6 & $25 \cdot 85$ & $1 \cdot 1$ \\
\hline Liver weight (g) & 1.14 & 0.06 & $1 \cdot 18$ & 0.08 & $1 \cdot 16$ & 0.02 & $1 \cdot 20$ & 0.04 \\
\hline Liver/body weight ratio (g) & $0.039^{a}$ & 0.000 & $0.045^{\mathrm{b}}$ & 0.002 & $0.043^{a, b}$ & 0.000 & $0.046^{b}$ & 0.002 \\
\hline Glucose $(\mathrm{mmol} / \mathrm{l})$ & $10 \cdot 3^{\mathrm{a}}$ & 0.4 & $9 \cdot 9^{\mathrm{a}}$ & 0.7 & $10 \cdot 1^{\mathrm{a}}$ & 0.6 & $12 \cdot 7^{\mathrm{b}}$ & 0.8 \\
\hline TAG $(\mathrm{mmol} / \mathrm{l})$ & $1 \cdot 1^{\mathrm{a}}$ & 0.3 & $2 \cdot 1^{\mathrm{b}}$ & 0.2 & $1 \cdot 5^{\mathrm{a}, \mathrm{b}}$ & 0.2 & $2 \cdot 2^{b}$ & 0.1 \\
\hline
\end{tabular}

CG, control group; TG, trans-fat group; PG, palm oil group; IG, interesterified fat group.

a,b Mean values with unlike superscript letters were significantly different between experimental groups $(P<0.05$ ANOVA, with Newman-Keuls post hoc test).

Table 4. Liver fatty acid profile (\% of total) from male offspring at $110 \mathrm{~d}$ of life (Mean values with their standard errors, $n$ 7-8)

\begin{tabular}{|c|c|c|c|c|c|c|c|c|}
\hline \multirow[b]{2}{*}{ Fatty acids } & \multicolumn{2}{|c|}{$C G$} & \multicolumn{2}{|c|}{ TG } & \multicolumn{2}{|c|}{$P G$} & \multicolumn{2}{|c|}{ IG } \\
\hline & Mean & SEM & Mean & SEM & Mean & SEM & Mean & SEM \\
\hline$\Sigma$ SFA & $28 \cdot 40$ & 1.43 & $31 \cdot 22$ & 0.68 & 31.09 & 0.63 & $30 \cdot 69$ & 0.76 \\
\hline C16:0 & $20 \cdot 82^{\mathrm{a}}$ & 1.41 & $13 \cdot 40^{\mathrm{b}}$ & 1.37 & $17 \cdot 37^{\mathrm{a}, \mathrm{b}}$ & 1.28 & $13.65^{\mathrm{b}}$ & 0.84 \\
\hline C18:0 & 8.00 & 1.29 & 9.03 & 0.61 & 8.73 & 0.75 & $8 \cdot 17$ & 0.47 \\
\hline ¿MUFA & $38 \cdot 84^{a}$ & 1.32 & $31.08^{b}$ & $2 \cdot 12$ & $32 \cdot 27^{b}$ & 1.08 & $32 \cdot 90^{\mathrm{b}}$ & 1.23 \\
\hline C18: $1 n-9$ (oleic) & $31.73^{\mathrm{a}}$ & 1.88 & $18 \cdot 54^{\mathrm{b}}$ & 1.34 & $24 \cdot 41^{\mathrm{b}}$ & 0.80 & $23 \cdot 36^{\mathrm{b}}$ & 1.29 \\
\hline$\Sigma$ PUFA & $31.00^{\mathrm{a}}$ & 1.32 & $24.53^{b}$ & 1.35 & $33 \cdot 23^{a}$ & 0.51 & $24 \cdot 72^{\mathrm{b}}$ & $2 \cdot 28$ \\
\hline C18:2n-6 (LA) & $18 \cdot 05^{\mathrm{a}}$ & 1.05 & $13 \cdot 24^{\mathrm{b}}$ & 0.84 & $19 \cdot 50^{\mathrm{a}}$ & 0.68 & $10 \cdot 64^{\mathrm{b}}$ & 0.45 \\
\hline $\mathrm{C} 20: 4 n-6$ (AA) & 8.46 & $1 \cdot 19$ & 7.92 & 0.77 & 7.97 & 0.61 & 7.57 & 0.71 \\
\hline C22: $5 n-6$ (DPA) & $0.36^{\mathrm{a}}$ & 0.01 & $0.24^{b}$ & 0.03 & $0.38^{\mathrm{a}}$ & 0.03 & $0.38^{\mathrm{a}}$ & 0.02 \\
\hline ¿PUFA $n-6$ & $26 \cdot 74^{\mathrm{a}}$ & 0.65 & $21.91^{b}$ & 1.42 & $28 \cdot 24^{\mathrm{a}}$ & 0.33 & $18.98^{\mathrm{b}}$ & 1.48 \\
\hline C18:3n-3 (ALA) & $1.44^{\mathrm{a}}$ & 0.05 & $0.98^{\mathrm{b}}$ & 0.01 & $1 \cdot 16^{\mathrm{C}}$ & 0.09 & $1 \cdot 15^{\mathrm{c}}$ & 0.04 \\
\hline C20:5n-3 (EPA) & $0.27^{a}$ & 0.01 & $0.18^{\mathrm{b}}$ & 0.00 & $0.25^{\mathrm{a}}$ & 0.01 & $0 \cdot 16^{b}$ & 0.00 \\
\hline $\mathrm{C} 22: 6 n-3$ (DHA) & 4.65 & 0.46 & 4.91 & 0.31 & 4.45 & 0.41 & 4.80 & 0.45 \\
\hline$\sum$ PUFA $n-3$ & 5.53 & 0.44 & $5 \cdot 87$ & 0.44 & $5 \cdot 17$ & 0.69 & $5 \cdot 28$ & 0.52 \\
\hline$\Sigma T F A$ & 1.27 & 0.09 & 1.47 & 0.07 & 1.25 & 0.08 & 1.45 & 0.08 \\
\hline$\Delta-9$ desaturase index $(\mathrm{C} 18: 1 / \mathrm{C} 18: 0)$ & $4 \cdot 28^{a}$ & 0.61 & $2 \cdot 28^{\mathrm{b}}$ & 0.21 & $2 \cdot 70^{\mathrm{b}}$ & 0.16 & $2 \cdot 91^{\mathrm{b}}$ & 0.11 \\
\hline$\Delta-6$ desaturase index $(C 18: 3 n-6 / C 18: 2 n-6)$ & $0.030^{\mathrm{a}}$ & 0.00 & $0.013^{b}$ & 0.00 & $0.019^{b}$ & 0.00 & $0.014^{\mathrm{b}}$ & 0.00 \\
\hline
\end{tabular}

CG, control group; TG, trans-fat group; PG, palm oil group; IG, interesterified fat group; TFA, trans-fatty acids; LA, linoleic acid; ALA, $a$-linolenic acid; AA, arachidonic acid. ${ }^{a, b, c}$ Mean values with unlike superscript letters were significantly different between experimental groups $(P<0.05$ ANOVA, with Newman-Keuls post hoc test).

We also evaluated the plasma glucose and TAG concentrations of male offspring. The results, shown in Table 3, demonstrate that the IG had plasma glucose levels increased by $1 \cdot 2$-fold in relation to the CG. Moreover, TAG plasma concentration was 1.8-fold in the TG and 1.9-fold higher in the IG when compared with the CG.

\section{Maternal consumption of trans-fat and its substitutes during pregnancy and lactation decreased MUFA and PUFA in offspring livers}

The data presented in Table 4 indicate that the composition of ¿SFA in the livers of adult offspring did not differ among groups. However, palmitic acid (C16:0) was significantly lower in the TG and IG compared with the CG. The content of $\Sigma$ MUFA decreased by $20,16.9$ and $15.3 \%$ in the TG, PG and IG, respectively, when compared with the CG. The decrease in oleic acid (C18:1n-9) contributed significantly to these differences.

Regarding the total amount of PUFA in the liver, $\Sigma$ PUFA in the TG and IG was significantly lower when compared with the CG and PG. In addition, $\Sigma$ PUFA $n-6$ in the TG and IG was also reduced. The essential $n-6$ precursor linoleic acid (LA) was lower in the TG and IG, even though arachidonic acid (AA), an important LA product, did not differ among groups. Moreover, $\Sigma$ PUFA $n$-3 did not vary significantly among the groups. On the other hand, essential $n$-3 $\alpha$-linolenic acid (ALA) was considerably lower in the TG (by31.9\%), PG (by 19.4\%) and the IG (by $20 \cdot 1 \%$ ) when compared with the CG. The decrease in ALA was associated with a decrease in its main $n-3$ derivatives, EPA content, in the TG and IG compared with the CG.

In addition, the ratios $\mathrm{C} 18: 1 / \mathrm{C} 18: 0$ and $\mathrm{C} 18: 3 n-6 / \mathrm{C} 18$ : $2 n-6$, which indicate $\Delta-9$ and $\Delta-6$ desaturation indexes, respectively, decreased significantly in all experimental groups (TG, PG and IG) when compared with the CG.

The source of dietary lipids during pregnancy and lactation caused mitochondrial changes in $\mathrm{VO}_{2}$ and respiratory states in the livers of adult offspring

To evaluate whether the maternal intake of fat substitutes for trans-fats could influence mitochondrial physiology, we used high-resolution respirometry to analyse samples of isolated liver mitochondria from male adult offspring to evaluate $\mathrm{VO}_{2}$ following the addition of respiratory substrates for Complex I (PMG) or Complex II (SUCC). 

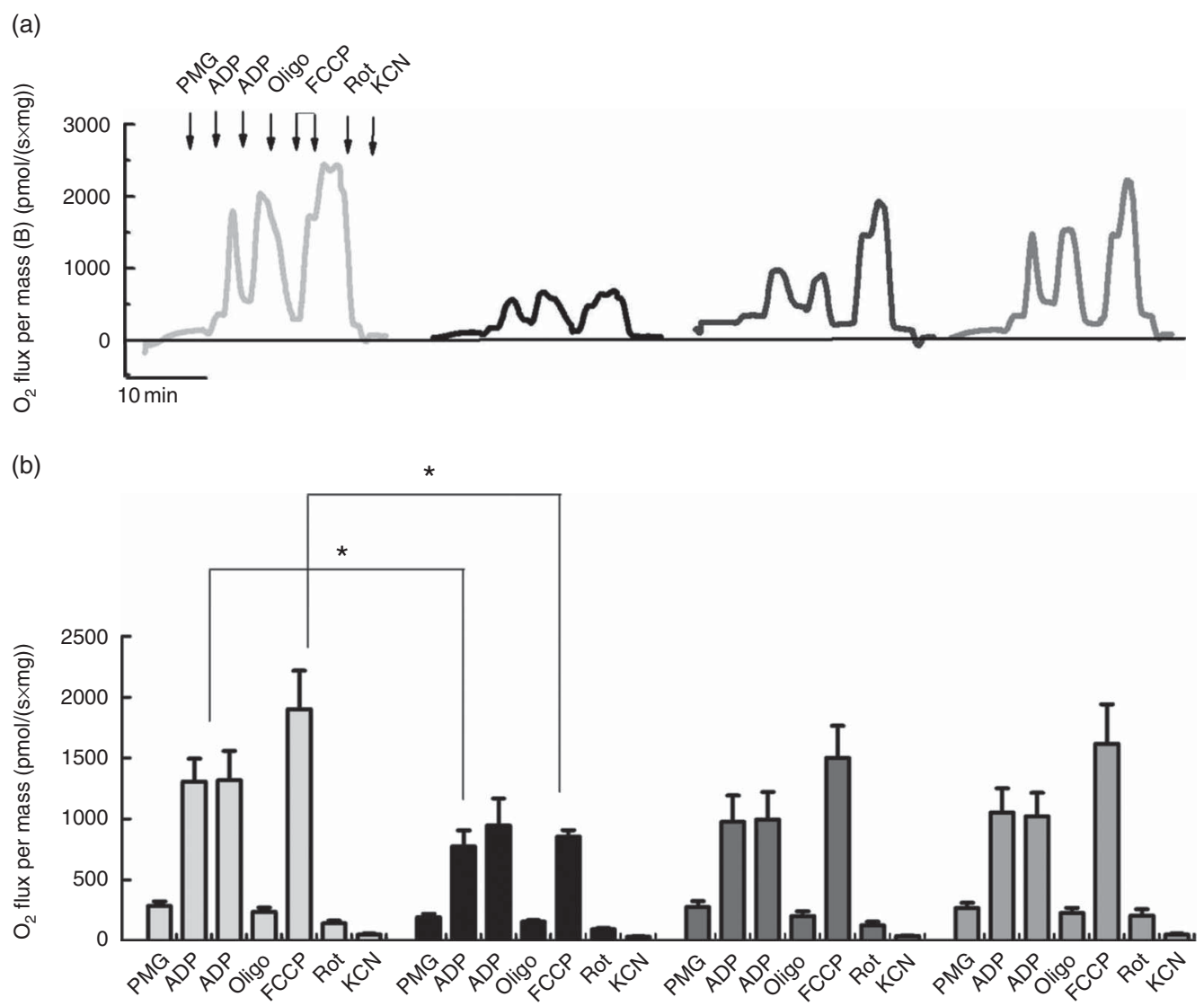

Fig. 2. Oxygen flux through complex I in high-resolution respirometry. (a) Oxygen flux per mass after multi-substrate experiments from control group (CG) ( $\square$ ), transfat group (TG) ( $\square$ ), palm oil group (PG) $(\square$ ) and interesterified fat group (IG) ( $\square$ ). (b) Quantitative analyses indicate that TG presented lower oxygen rates after sequential addition in relation to all experimental groups. Significant reduced values were seen in TG after ADP and carbonyl cyanide-4-(trifluoromethoxy) phenylhydrazone (FCCP) when compared with CG. Pyruvate/malate/glutamate (PMG, $2 \mathrm{~mm}$ each), ADP $(100 \mu \mathrm{M})$, ADP $(1 \mathrm{~mm})$, oligomycin $(\mathrm{Oligo}, 2 \mu \mathrm{g} / \mathrm{ml})$, FCCP $(0.5 \mu \mathrm{M})$, rotenone (Rot, $0.5 \mu \mathrm{M})$ and potassium cyanide $(\mathrm{KCN}, 2 \mathrm{mM})$. Results were expressed in pmol oxygen/mg protein $\times \mathrm{s}$. Values are expressed as means $(n-8)$, with their standard errors represented by vertical bars. ${ }^{*} P<0.05$.

Fig. 2(a) shows representative $\mathrm{VO}_{2}$ rates of each experimental group in the presence of PMG. The values shown in Fig. 2(b) indicate that the TG exhibited lower rates of $\mathrm{VO}_{2}$ of all respiratory substrates studied, with significant differences in the presence of $\mathrm{ADP}$ and FCCP, in relation to the CG.

Moreover, when we analysed the $\mathrm{O}_{2}$ flux through complex II after SUCC addition, we also detected lower rates of $\mathrm{VO}_{2}$ in liver mitochondria from the TG (Fig. 3(a)). Quantitative results confirmed the observations, with the TG displaying the lowest rates throughout the additions, with significantly reduced values after FCCP, when compared with the PG (Fig. 3(b)).

Average respiratory rates and respiratory parameters are presented in the online Supplementary Tables S1 and S2 after PMG and SUCC addition. It can be observed that when PMG were the respiratory substrates, the TG presented a significant $(56 \%)$ reduction in the electron transfer system (ETS) capacity, which corresponded to maximal respiration recorded after FCCP titration, when compared with the CG $(P=0.0354)$.

The results of respiratory parameters after complex II substrate addition indicated that the TG indeed presented important alterations in mitochondrial bioenergetics (online
Supplementary Table S2). A significant (50.0\%) decrease in ETS capacity was observed in the TG in relation to the PG. In addition, the IG also displayed a slight reduction when compared with the CG and PG. On the other hand, contrary to what was observed after PMG addition, the PG presented similar respiratory rates to the CG. These findings suggest that the metabolic programming induced by trans-fat involved alterations in the control of coupled respiration by the phosphorylation system. Leak flux control ratio, which reflects the extent of intrinsic uncoupling, was not different among the groups (online Supplementary Table S2).

In an attempt to better understand the association between oxidative phosphorylation and ETS capacities of liver mitochondria in the context of metabolic programming, we subtracted the oxidative phosphorylation capacity rate from the ETS capacity rate (Fig. 4). By doing so, respiratory reserve capacity is represented as an absolute respiratory rate, as opposed to a fraction of maximal respiration. It is clear that the TG presented no reserve capacity when compared with all other groups $(P=0.0207)$, when PMG were the respiratory substrates.

CS activity was measured in livers of mouse offspring as a marker of mitochondrial content. The results showed no 
(a)
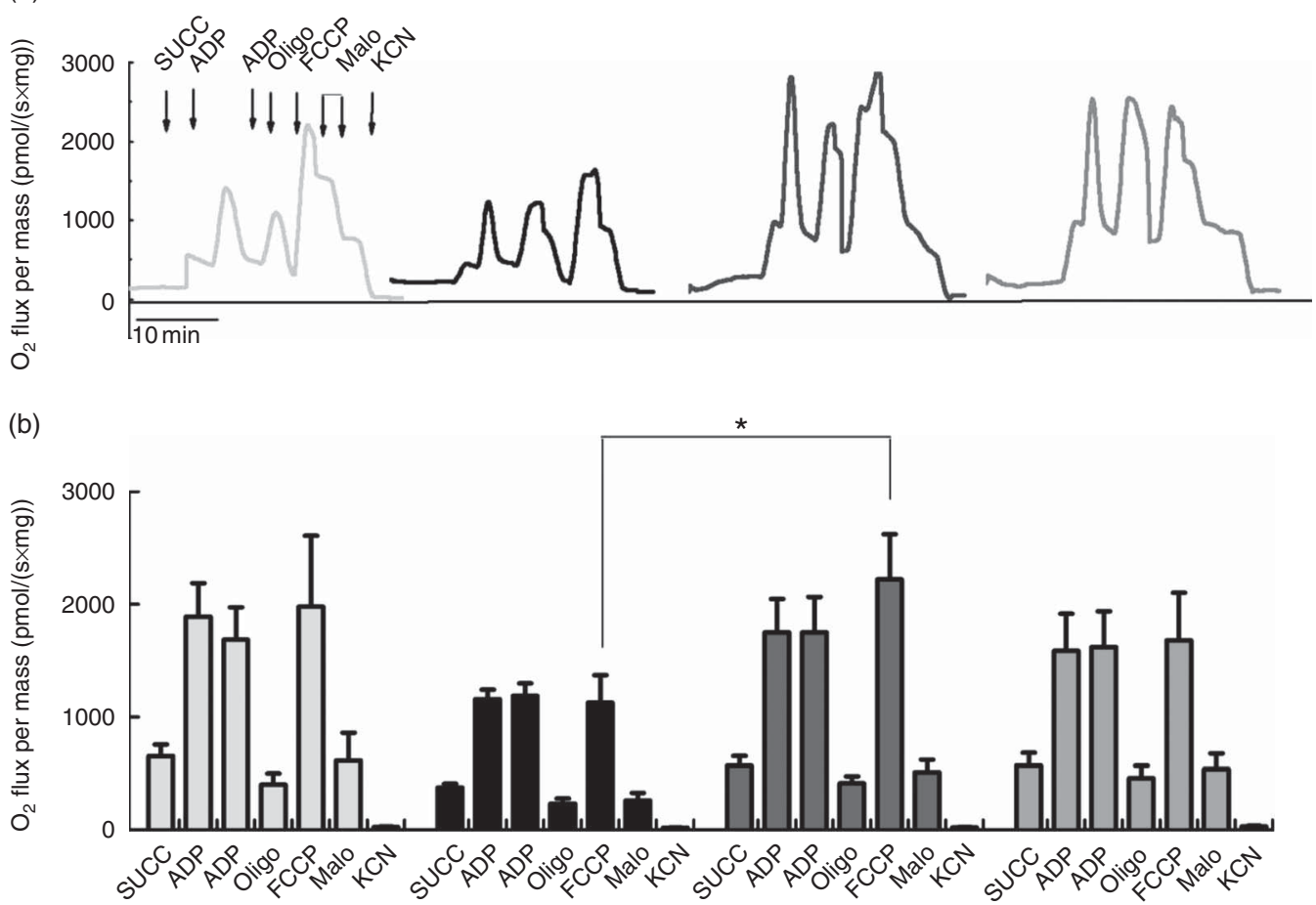

Fig. 3. Oxygen flux through complex II in high-resolution respirometry. (a) Oxygen flux per mass after multi-substrates experiments from control group (CG) ( $\square$ ), trans-

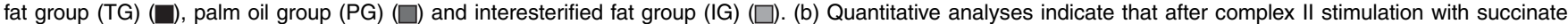
(SUCC), TG also displayed reduced oxygen rates in relation to all groups. Statistically different values were seen in TG after carbonyl cyanide-4-(trifluoromethoxy) phenylhydrazone (FCCP) when compared with PG. SUCC $(2 \mathrm{~mm})$, ADP $(100 \mu \mathrm{M})$, ADP $(1 \mathrm{~mm})$, oligomycin (Oligo, $2 \mu \mathrm{g} / \mathrm{ml})$, FCCP $(0.5 \mu \mathrm{M})$, malonate $(\mathrm{Malo}, 5 \mathrm{mM})$ and potassium cyanide $(\mathrm{KCN}, 2 \mathrm{mM})$. Results were expressed in pmol oxygen $/ \mathrm{mg}$ of protein $\times \mathrm{s}$. Values are expressed as means $(n-8)$, with their standard errors represented by vertical bars. ${ }^{*} P<0.05$.

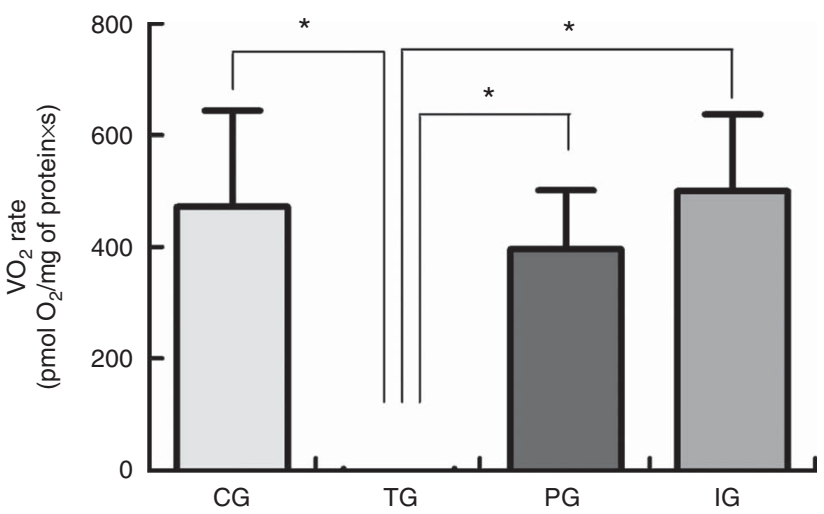

Fig. 4. Reserve capacity from liver mitochondria of adult offspring. Quantitative results from $\mathrm{VO}_{2}$ rate (the difference of the electron transfer system capacity and oxidative phosphorylation capacity) showed that offspring that received, during pregnancy and lactation, trans-fat group (TG) presented no reserve capacity, suggesting that liver mitochondria from TG work under its maximum capacitance. Results were expressed in pmol oxygen/mg of protein $\times s$. Values are expressed as means (n 7-8), with their standard errors represented by vertical bars. CG, control group; PG, palm oil group; IG, interesterified fat group. ${ }^{*} P<0.05$.

differences among all experimental groups where the mean results were $51 \cdot 40$ ( (SЕм 3.19), $45 \cdot 39$ (SEM 2.09), $46 \cdot 81$ (SЕM 4.45) and $43.29($ SEM 1.8$) \mathrm{nmol} \times \mathrm{mg} /$ protein $\times$ min for the CG, TG, PG and IG, respectively. These results indicate that the effects on mitochondrial respiratory parameters were not related to the decreased mitochondrial contents in any of the experimental groups.

\section{Hydrogen peroxide production rates from oxidative and non-oxidative phosphorylation in isolated liver mitochondria from adult offspring}

Next, we evaluated $\mathrm{H}_{2} \mathrm{O}_{2}$ production in intact liver mitochondria. When complex II was activated by SUCC, $\mathrm{H}_{2} \mathrm{O}_{2}$ rates were significantly different $(P=0.0013)$ in the IG, increasing 1.4-fold when compared with the CG (Fig. 5). In addition, the TG showed reduced levels after the sequential additions, which supports that trans-fat presented low production of $\mathrm{H}_{2} \mathrm{O}_{2}$ in liver mitochondria.

$\mathrm{H}_{2} \mathrm{O}_{2}$ generation through mitochondria induced by complex I was undetectable, as we observed that the $\mathrm{H}_{2} \mathrm{O}_{2}$ flux under basal conditions and after PMG addition changed slightly (online Supplementary Fig. S1). This result suggests that the $\mathrm{H}_{2} \mathrm{O}_{2}$ flux detected could be related to production by a non-oxidative phosphorylation, which responds differently to that generally observed in functional mitochondria. Therefore, $\mathrm{H}_{2} \mathrm{O}_{2}$ generation by extra-mitochondrial fractions tended to increase in the IG and PG, compared with the CG, whereas the TG clearly showed reduced $\mathrm{H}_{2} \mathrm{O}_{2}$ levels. The data indicate that dietary fat induced $\mathrm{H}_{2} \mathrm{O}_{2}$ production by other factors, possibly related to pro-inflammatory mechanisms. 
(a)

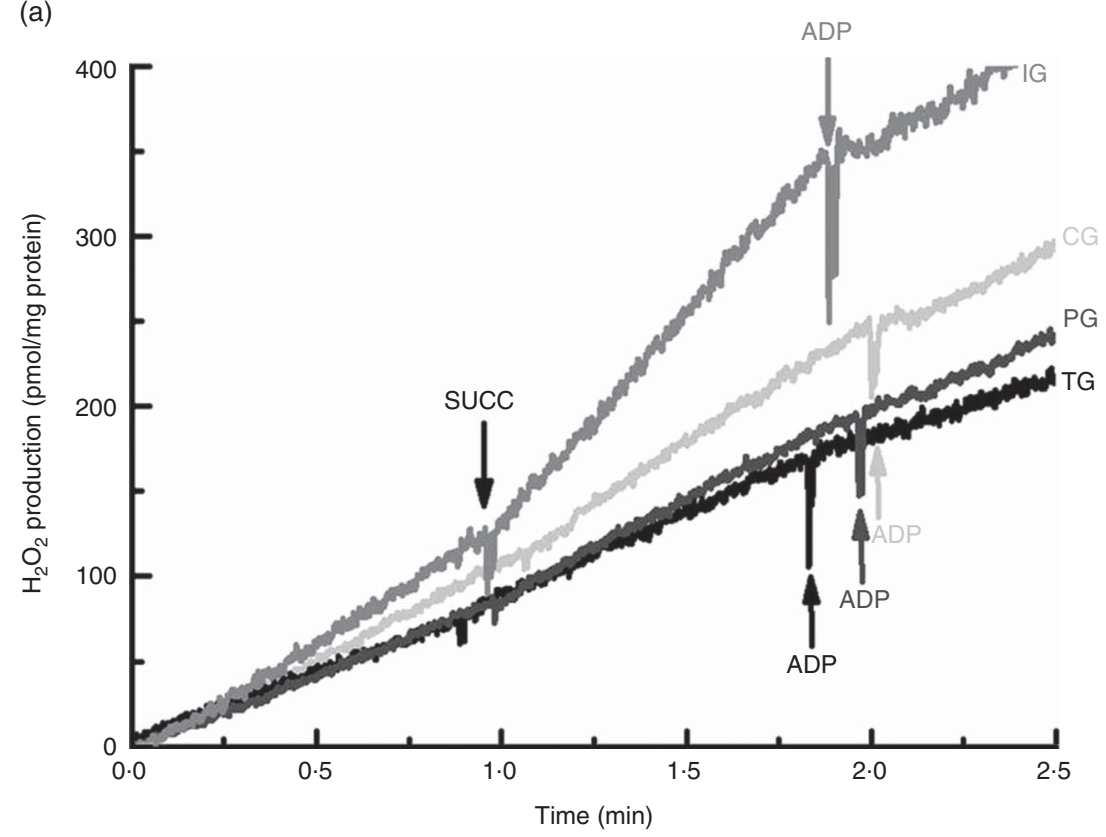

(b)

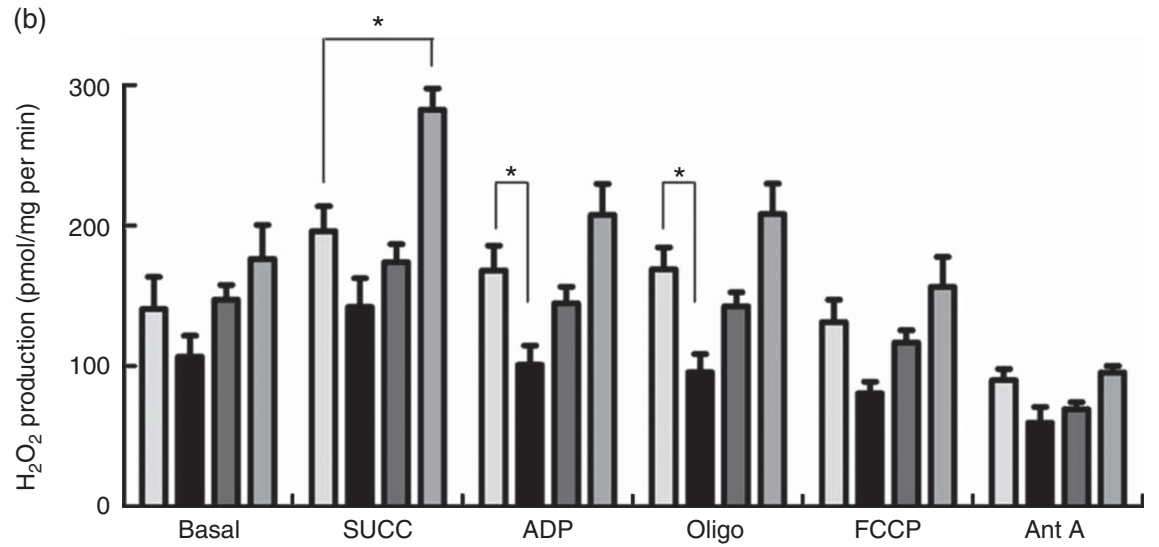

Fig. 5. Hydrogen peroxide $\left(\mathrm{H}_{2} \mathrm{O}_{2}\right)$ production using multiple titrations. (a) The representative graph of $\mathrm{H}_{2} \mathrm{O}_{2}$ rates measured after complex II stimulation with succinate (SUCC). Interesterified fat group (IG, $\square$ ) increased $\mathrm{H}_{2} \mathrm{O}_{2}$ production when compared with all experimental groups. Trans-fat group (TG, $\square$ ) presented reduced $\mathrm{H}_{2} \mathrm{O}_{2}$ production throughout multiple additions. (b) The quantitative results indicate that levels of $\mathrm{H}_{2} \mathrm{O}_{2}$ increased after substrate stimulation in IG. The experiments were done with sequential addition of substrates from SUCC $(2 \mathrm{~mm})$, followed by $0.5 \mathrm{~mm} \mathrm{ADP,} 2 \mu \mathrm{g} / \mathrm{ml}$ oligomycin (Oligo), $0.5 \mu \mathrm{m}$ carbonyl cyanide-4-(trifluoromethoxy) phenylhydrazone (FCCP) and $5 \mu \mathrm{m}$ antimycin A (Ant A). Results were expressed in pmol $\mathrm{H}_{2} \mathrm{O}_{2} / \mathrm{mg}$ of protein $\times$ min. Values are expressed as means $(n 7-8)$, with their standard errors represented by vertical bars. $\square$, control group (CG); $\square$, palm oil group (PG). ${ }^{*} P<0.05$.

\section{Interesterified fat induced an increase in electron leakage} ratio using succinate as substrate

As we observed altered patterns in mitochondrial $\mathrm{VO}_{2}$ and $\mathrm{H}_{2} \mathrm{O}_{2}$ production rates after complex II activation, we next sought to evaluate the impact of those changes on mitochondrial electron leakage. After SUCC addition, we found a significant increase ( $P=0.0156)$ in the electron leakage rate in the IG when compared with the CG, confirming the highest levels in $\mathrm{H}_{2} \mathrm{O}_{2}$ mitochondrial production compared with the other groups (Table 5).

\section{Dietary intake of trans-fat or interesterified fat during pregnancy and lactation reduced $\mathrm{Ca}^{2+}$ retention capacity in liver mitochondria}

We investigated whether maternal dietary intake of trans-fat, PO or IF could affect MPTP susceptibility in isolated
Table 5. Electron leakage for hydrogen peroxide $\left(\mathrm{H}_{2} \mathrm{O}_{2}\right)$ formation in liver mitochondria with succinate (SUCC)

(Mean values with their standard errors, $n 7-8$ )

\begin{tabular}{|c|c|c|c|c|c|c|}
\hline & \multicolumn{2}{|c|}{$\begin{array}{c}\text { (A) } \mathrm{H}_{2} \mathrm{O}_{2} \text { production (nmol/ } \\
\text { mg protein } \times \text { min) (state } 2 \\
\text { with SUCC) } \\
\end{array}$} & \multicolumn{2}{|c|}{$\begin{array}{c}(\mathrm{B}) \mathrm{VO}_{2}(\mathrm{nmol} / \mathrm{mg} \\
\text { protein } \times \text { min) }(\text { state } 2 \\
\text { with SUCC) } \\
\end{array}$} & \multicolumn{2}{|c|}{$\mathrm{A} / \mathrm{B}\left(\times 10^{-3}\right)$} \\
\hline & Mean & SEM & Mean & SEM & Mean & SEM \\
\hline CG & 0.173025 & 0.027 & 39.34526 & 4.64 & 4.398 & 1.00 \\
\hline TG & 0.142241 & 0.020 & $22 \cdot 73716$ & 1.87 & $6 \cdot 256$ & 1.44 \\
\hline$P G$ & 0.208808 & 0.036 & $34 \cdot 20484$ & $5 \cdot 36$ & $6 \cdot 105$ & $1 \cdot 164$ \\
\hline IG & $0.282251^{*}$ & 0.016 & 34.3811 & $5 \cdot 17$ & $8.209^{*}$ & 0.81 \\
\hline
\end{tabular}


liver mitochondria from mouse offspring. The mitochondrial $\mathrm{Ca}^{2+}$ retention capacities are shown in Fig. 6. A representative graph showing all groups is demonstrated in Fig. 6(A)

(A)

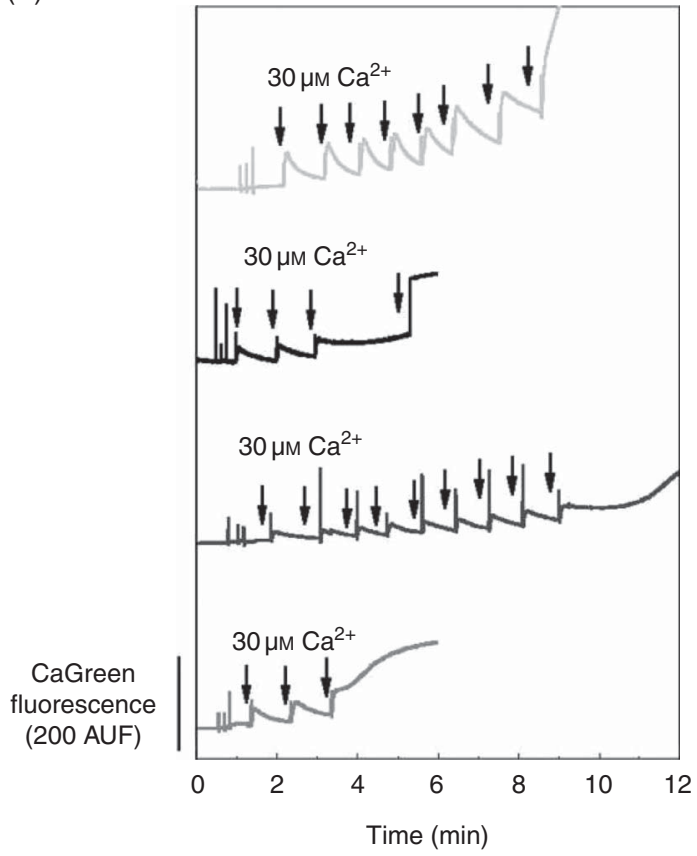

and (B), in response to sequential additions of $\mathrm{CaCl}_{2}$ (30 $\mu$ mol every minute) until mitochondrial swelling and $\mathrm{Ca}^{2+}$ release.

(B)

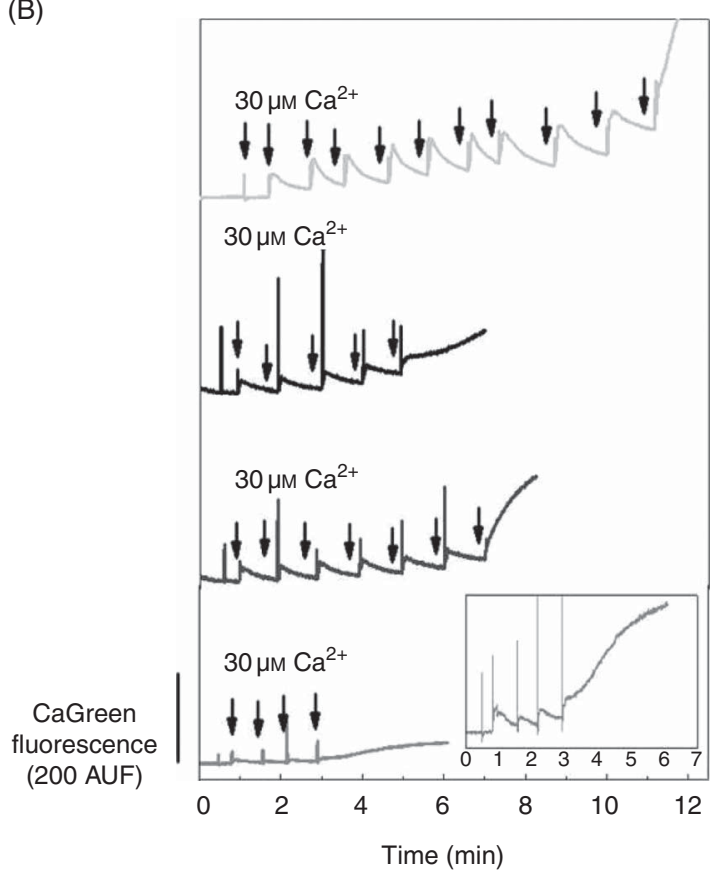

(D)

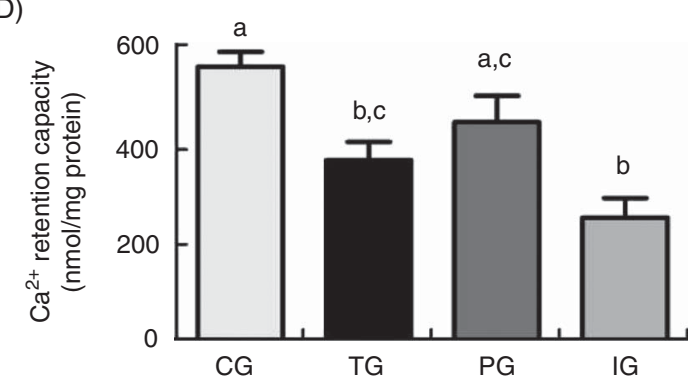

$(\mathrm{F})$

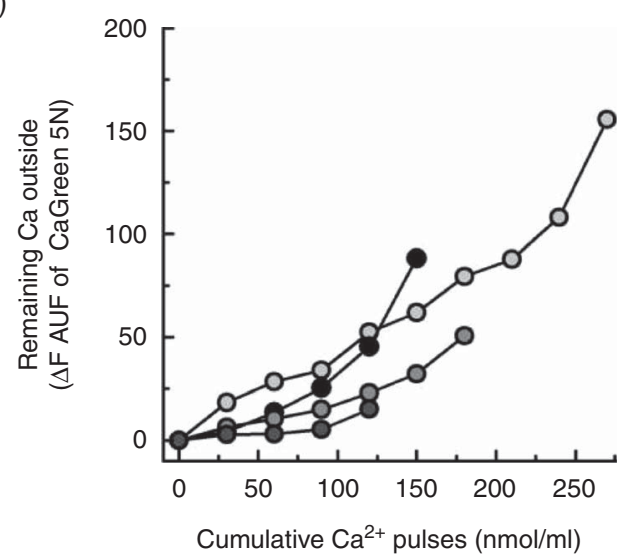

Fig. 6. Determination of calcium retention capacity in liver mitochondria. (A) and (B) Representation of calcium uptake through liver mitochondria from all groups after sequential additions of calcium chloride $(30 \mu \mathrm{M})$. The range of the inset is 50 AUF. Quantitative results confirmed that trans-fat group (TG) and interesterified fat group (IG) presented less retention capacity after pyruvate/malate/glutamate (C) and succinate (D). In addition, TG and IG differ in calcium levels remaining outside the mitochondria $(E)$ and $(F)$. Values are expressed as means $(n 7-8)$, with their standard errors represented by vertical bars. CG, control group; PG, palm oil group;

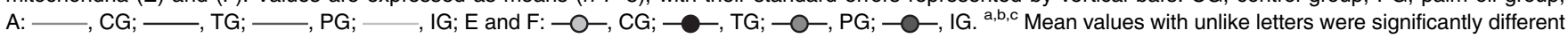
between experimental groups $(P<0.05$ ANOVA, with Newman-Keuls post hoc test). 
The quantitative results indicate that after activation of complex I (Fig. 6(C)) with PMG, the TG and IG displayed a $44 \%(P=0.0163)$ and $58 \%(P=0.0018)$ reduction in $\mathrm{Ca}^{2+}$ retention, respectively, in relation to the CG. The PG did not differ from the CG. When complex II was activated with SUCC (Fig. 6(D)), we observed a similar pattern, as the TG and IG also presented a $34 \%(P=0.0215)$ and $55 \%(P=0.0002)$ reduction in $\mathrm{Ca}^{2+}$ retention, respectively, when compared with the CG.

Thereafter, we analysed the differences among groups in relation to the remaining $\mathrm{Ca}^{2+}$ levels outside the mitochondria before MPTP opening - that is, the $\mathrm{Ca}^{2+}$ dose-dependence for MPTP opening after PMG (Fig. 6(E)) and SUCC (Fig. 6(F)). The data indicate that different $\mathrm{Ca}^{2+}$ retention dynamics in the TG and IG, after introducing PMG, presented less cumulative $\mathrm{Ca}^{2+}$ pulses and $\mathrm{Ca}^{2+}$ releases out of mitochondria faster than the PG and CG. After SUCC, we could also infer that cumulative pulses before MPTP opening were reduced in the TG and IG, suggesting that the liver mitochondria of offspring from these groups do not tolerate elevated $\mathrm{Ca}^{2+}$ concentrations.

\section{Discussion}

In this study, we were able to demonstrate, for the first time, that the intake of normolipidic diets containing trans-fat and its substitute, IF, during pregnancy and lactation predisposes the adult offspring to liver mitochondrial dysfunction, related to alterations in the redox state. Modifications in mitochondrial bioenergetics included impairment in $\mathrm{VO}_{2}$ in the TG and increased $\mathrm{H}_{2} \mathrm{O}_{2}$ production in the IG. In both groups, mitochondrial membrane permeability was compromised, as evidenced by a decreased capacity for $\mathrm{Ca}^{2+}$ uptake. In addition, our results demonstrate that liver mitochondrial dysfunction was accompanied by impaired glucose homoeostasis and alterations in plasma and liver lipids profile, favouring the onset of steatosis and CVD (Table 3). These results suggest an association between early life exposure to trans-unsaturated and interesterified FA and an increased risk for developing chronic metabolic diseases in adulthood ${ }^{(15,16)}$.

Fat accumulation in the liver can be associated with local oxidative stress, impaired mitochondrial FA oxidation and inflammation, which may damage the liver ${ }^{(37,38)}$. At 110 days of life, the liver/body weight ratio was significantly higher in the TG and IG when compared with the CG and PG (Table 3). Indeed, our findings show that the IG presented higher levels of plasma glucose and the IG and TG presented increased TAG plasma concentration. These results may indicate a higher content of fat in the offspring's livers from these groups, which may contribute to an imbalance in lipid metabolism in the liver and other tissues, although additional analysis is necessary to confirm fat accumulation in the liver.

The composition of liver FA showed that the TG and IG offspring presented a lower amount of total MUFA, total PUFA, LA and ALA (Table 4). In addition, the desaturation indexes, using the ratios C18:1/C18:0 and $\mathrm{C} 18: 3 n-6 / \mathrm{C} 18: 2 n-6$, were significantly decreased in the TG and IG, despite the lack of differences in AA $(20: 4 n-6)$ and DHA $(22: 6 n-3)$ contents. This alteration in the metabolism of unsaturated FA could have consequences on membrane fluidity, phospholipid composition and the activity of channels, proteins and transporters in the liver ${ }^{(39)}$. In addition, modifications in phospholipids composition induced by maternal diet in mitochondria-associated membranes (MAM) could interfere with the communication between mitochondria and endoplasmic reticulum $(\mathrm{ER})^{(40)}$. Here we addressed the question whether mitochondrial bioenergetics plays a role in liver function and metabolic abnormalities induced by the maternal intake of different FA. Nevertheless, changes of FA in the mitochondria per se induced by the maternal intake of different FA cannot be completely excluded.

Mitochondrial phospholipids play crucial roles in mitochondrial function, as they regulate organelle fission and fusion, mitophagy and apoptosis ${ }^{(41)}$. Furthermore, obesity is associated with impaired mitochondrial function ${ }^{(17)}$. In the present study, we observed that the TG displayed the lowest $\mathrm{VO}_{2}$ rates in liver mitochondria among all the groups of offspring (Fig. 2 and 3). In addition, ETS capacity $\left(\mathrm{VO}_{2}\right.$ rate induced by FCCP) was lower in the TG compared with the CG (online Supplementary Data). This reduction in ETS capacity also caused a decrease in respiratory reserve capacity (Fig. 4), indicating that liver mitochondria from TG offspring is already working near their bioenergetics limit, possibly because of alterations in mitochondrial architecture ${ }^{(42)}$ and/or respiratory complex activities $^{(7)}$. The respiratory parameters in the IG were not significantly affected when compared with the CG and PG (Fig. 2 and 3), despite the same alterations in unsaturated FA composition and glucose homoeostasis observed in the TG (Tables 3 and 4). Thus, the IG demonstrated an essential change in phospholipids of the inner mitochondrial membrane, but we were not able to detect changes in oxygen consumption. These findings provide additional support for efforts to reduce industrial TFA in foods in general. In agreement with our results, it has been shown that a diet containing fish oil, rich in $n$-3 long-chain PUFA, compared with lard fat, rich in SFA, improved mitochondrial function, whereas lard fat decreased the mitochondrial respiratory control ratio and respiration associated with complex I and complex II ${ }^{(5)}$. In addition, highfat diets, rich in SFA, prompted hepatic fat accumulation and insulin resistance, which were associated with impaired mitochondrial function, increased ROS production and a dysregulated expression profile of mitochondrial dynamic proteins ${ }^{(22)}$.

Mitochondria can be an important source of ROS/RNS production and mitochondrial bioenergetics is directly involved in this characteristic $^{(43)}$. Even though the TG presented significant alterations in mitochondrial respiratory parameters, the $\mathrm{H}_{2} \mathrm{O}_{2}$ production rate was the lowest among all the groups. Nevertheless, the IG demonstrated an increase in $\mathrm{H}_{2} \mathrm{O}_{2}$ production after complex II stimulation (Fig. 5). As $\mathrm{H}_{2} \mathrm{O}_{2}$ production was correlated to electron leakage (Table 5), several aspects related to redox signalling are worth discussing. The decrease in $\mathrm{H}_{2} \mathrm{O}_{2}$ production observed in the TG might reflect a decrease in mitochondrial $\mathrm{O}_{2}$ flux (Fig. 2 and 3), which could be the result of decreased activities of ETS proteins, which, in turn, decreased the escape of electrons and ROS production. On the other hand, the significant increase in $\mathrm{H}_{2} \mathrm{O}_{2}$ production and electron leakage in the IG strongly suggest that specific alterations in spatial arrangements of ETS proteins are involved in mitochondrial dysfunction, possibly associated with the opening of the MPTP ${ }^{(44)}$. 
The results presented in Fig. 6 show that liver mitochondria of the TG and IG adult offspring are more susceptible to MPTP opening, as the mitochondrial capacity for handling $\mathrm{Ca}^{2+}$ loads is significantly decreased in both groups when compared with the CG and PG. Arruda et al. ${ }^{(45)}$ has demonstrated that in cases of obesity the liver is susceptible to a marked reorganisation by physical interaction between ER and mitochondria, through $\mathrm{MAM}^{(46)}$, which was shown to be dependent on the palmitoylation state in cysteine residues ${ }^{(45)}$. Our data indicate that the TG and IG presented reduced levels of palmitic acid (Table 4), which can result in a different state of palmitoylation and regulation of $\mathrm{Ca}^{2+}$ homoeostasis. Further studies are necessary to confirm this interaction between diet and MAM.

Alterations in mitochondrial membrane permeability and function are strongly related to the composition of the phospholipid cardiolipin (CL). The main fatty acyl moiety in CL is LA, with $60-80 \%$ of CL being tetralinoleoyl CL and it has been proposed that high amounts of tetralinoleoyl CL are essential for optimal mitochondrial function ${ }^{(47)}$. Indeed, the adult offspring from dams fed TFA or and interesterified FA presented decreased contents of LA. In addition, the desaturation index is lower in the TG and IG. Therefore, it is plausible to assume that alterations in mitochondrial cardiolipin metabolism induced by the maternal diet might be involved in liver mitochondrial dysfunction. An increase in LA content in liver mitochondria induced by MitoQ has been associated with improved mitochondrial function and the prevention of some factors of metabolic syndrome in mice fed an obesogenic diet ${ }^{(48)}$.

Mitochondrial dysfunction as a consequence of alterations in FA metabolism in the liver is possibly mediated by epigenetic events. Accordingly, the decrease in $\Delta 6$ desaturase index observed in all three experimental groups compared with control animals (Table 4) could be related to a decreased expression of Fads 2 gene mRNA expression, encoding for $\Delta 6$ desaturase, the rate-limiting enzyme in PUFA synthesis, as it has been shown that a high-fat diet during pregnancy and lactation increased the methylation of this gene in the adult offspring, regulating PUFA metabolism in the liver ${ }^{(49)}$

The implications of the types of FA consumed during pregnancy and lactation can lead to the development of noncommunicable diseases, as well as affecting fetus maturation and postnatal development. Altogether, our results imply that the consumption of trans-fat and its substitutes during critical stages of life could lead to impairments in the metabolism and development of offspring and to a 'programming' of long-term modifications in mitochondrial bioenergetics that might negatively impact metabolic outcomes in adult life. These observations suggest that we should be concerned with the use of PO, partially hydrogenated vegetable fat and IF by the food industry. We recommend monitoring the dietary consumption of trans-fat and SFA of pregnant and lactating women.

\section{Acknowledgements}

The authors thank the Brazilian Company Triângulo Alimentos Ltda, Itápolis, SP, Brazil (http://www.trianguloalimentos.com. br) for supplying the fats.
This work was supported by grants from Coordenação de Aperfeiçoamento de Pessoal de Nível Superior, Fundação de Amparo à Pesquisa do Estado do Rio de Janeiro and ConselhoNacional de DesenvolvimentoCientífico e Tecnológico.

P. C. d. V., G. C., D. M. R.-F., R. M. A. R. d. S., T. E.-B., A. G. and M. d. G. T.d.-C.: contributed to the assembly, analysis and interpretation and manuscript drafting; P. C. d. V., G. C., D. M. R.-F., R. M. A. R. d. S., T. E.-B., A. G., C. M. and M. d. G. T.d.-C.: contributed to the data collection; P. C. d. V., G. C., D. M. R.-F., R. M. A. R. d. S., T. E.-B., A. G. and M. d. G. T.d.-C., C. M. and F. L. C. S. approval of the final version of the manuscript; P. C. d. V., G. C., D. M. R.-F., R. M. A. R. d. S., T. E.-B., A. G. and M. d. G. T.d.-C. and F. L. C. S.: contributed to the study conception and design.

None of the authors has any conflicts of interest to declare.

\section{Supplementary material}

For supplementary material/s referred to in this article, please visit https://doi.org/10.1017/S0007114517001817

\section{References}

1. Barker DJ (2004) The developmental origins of adult disease. J Am Coll Nut 23, 588S-595S.

2. Spencer SJ (2012) Early life programming of obesity: the impact of the perinatal environment on the development of obesity and metabolic dysfunction in the offspring. Curr Diabetes Rev 8, 55-68.

3. Bruce KD \& Hanson MA (2010) The developmental origins, mechanisms, and implications of metabolic syndrome. J Nutr 140, 648-652.

4. Innis SM (2011) Metabolic programming of long-term outcomes due to fatty acid nutrition in early life. Matern Child Nutr 7, Suppl. 2, 112-123.

5. Aoun M, Feillet-Coudray C, Fouret G, et al. (2012) Rat liver mitochondrial membrane characteristics and mitochondrial functions are more profoundly altered by dietary lipid quantity than by dietary lipid quality: effect of different nutritional lipid patterns. Br J Nutr 107, 647-659.

6. Mennitti LV, Oliveira JL, Morais CA, et al. (2015) Type of fatty acids in maternal diets during pregnancy and/or lactation and metabolic consequences of the offspring. J Nutr Biochem 26, 99-111.

7. Chen C \& Bazan NG (2005) Lipid signaling: sleep, synaptic plasticity, and neuroprotection. Prostaglandins Other Lipid Mediat 77, 65-76.

8. Tontonoz P \& Spiegelman BM (2008) Fat and beyond: the diverse biology of PPARgamma. Annu Rev Biochem 77, 289-312.

9. Burdge GC \& Lillycrop KA (2014) Fatty acids and epigenetics. Curr Opin Clin Nutr Metab Care 17, 156-161.

10. Osso FS, Moreira AS, Teixeira MT, et al. (2008) Trans fatty acids in maternal milk lead to cardiac insulin resistance in adult offspring. Nutrition 24, 727-732.

11. Anderson AK, McDougald DM \& Steiner-Asiedu M (2010) Dietary trans fatty acid intake and maternal and infant adiposity. Eur J Clin Nutr 64, 1308-1315.

12. Oguntibeju OO, Esterhuyse AJ \& Truter EJ (2009) Red palm oil: nutritional, physiological and therapeutic roles in improving human wellbeing and quality of life. Br J Biomed Sci 66, 216-222.

13. Ong AS \& Goh SH (2002) Palm oil: a healthful and costeffective dietary component. Food Nutr Bul 23, 11-22. 
14. Berry SE (2009) Triacylglycerol structure and interesterification of palmitic and stearic acid-rich fats: an overview and implications for cardiovascular disease. Nutr Res Rev 22, 3-17.

15. Magri TP, Fernandes FS, Souza AS, et al. (2015) Interesterified fat or palm oil as substitutes for partially hydrogenated fat in maternal diet can predispose obesity in adult male offspring. Clin Nutr 34, 904-910.

16. Misan V, Estato V, de Velasco PC, et al. (2015) Interesterified fat or palm oil as substitutes for partially hydrogenated fat during the perinatal period produces changes in the brain fatty acids profile and increases leukocyte-endothelial interactions in the cerebral microcirculation from the male offspring in adult life. Brain Res 1616, 123-133.

17. Putti R, Sica R, Migliaccio V, et al. (2015) Diet impact on mitochondrial bioenergetics and dynamics. Front Physiol 6, 109.

18. Yu L, Fink BD, Herlein JA, et al. (2014) Dietary fat, fatty acid saturation and mitochondrial bioenergetics. J Bioenerg Biomembr 46, 33-44.

19. Khairallah RJ, O'Shea KM, Brown BH, et al. (2010) Treatment with docosahexaenoic acid, but not eicosapentaenoic acid, delays $\mathrm{Ca} 2+$-induced mitochondria permeability transition in normal and hypertrophied myocardium. J Pharmacol Exp Ther 335, 155-162.

20. Ronchi JA, Vercesi AE \& Castilho RF (2011) Reactive oxygen species and permeability transition pore in rat liver and kidney mitoplasts. J Bioenerg Biomembr 43, 709-715.

21. Kahle M, Schafer A, Seelig A, et al. (2015) High fat dietinduced modifications in membrane lipid and mitochondrialmembrane protein signatures precede the development of hepatic insulin resistance in mice. Mol Metab 4, 39-50.

22. Lionetti L, Mollica MP, Donizzetti I, et al. (2014) High-lard and high-fish-oil diets differ in their effects on function and dynamic behaviour of rat hepatic mitochondria. PLOS ONE $\mathbf{9}$, e92753.

23. Fink BD, Herlein JA, Almind K, et al. (2007) Mitochondrial proton leak in obesity-resistant and obesity-prone mice. $A m J$ Physiol Regul Integr Comp Physiol 293, R1773-R1780.

24. Borengasser SJ, Faske J, Kang P, et al. (2014) In utero exposure to prepregnancy maternal obesity and postweaning highfat diet impair regulators of mitochondrial dynamics in rat placenta and offspring. Physiol Genomics 46, 841-850.

25. Hellgren LI, Jensen RI, Waterstradt MS, et al. (2014) Acute and perinatal programming effects of a fat-rich diet on rat muscle mitochondrial function and hepatic lipid accumulation. Acta Obstet Gynecol Scand 93, 1170-1180.

26. Reeves PG, Nielsen FH \& Fahey GC Jr (1993) AIN-93 purified diets for laboratory rodents: final report of the American Institute of Nutrition ad hoc writing committee on the reformulation of the AIN-76A rodent diet. J Nutr 123, 1939-1951.

27. Frezza C, Cipolat S \& Scorrano L (2007) Organelle isolation: functional mitochondria from mouse liver, muscle and cultured fibroblasts. Nat Protoc 2, 287-295.

28. Meyer LE, Machado LB, Santiago AP, et al. (2006) Mitochondrial creatine kinase activity prevents reactive oxygen species generation: antioxidant role of mitochondrial kinase-dependent ADP re-cycling activity. J Biol Chem 281, 37361-37371.

29. Lowry OH, Rosebrough NJ, Farr AL, et al. (1951) Protein measurement with the Folin phenol reagent. J Biol Chem 193, 265-275.

30. Gnaiger E, Kuznetsov AV, Schneeberger S, et al. (2000) Mitochondria in the cold. In Life in the Cold, pp. 431-442 [G Heldmaier and $M$ Klingenspor, editors]. Berlin and Heidelberg: Springer.
31. Pesta D \& Gnaiger E (2012) High-resolution respirometry: OXPHOS protocols for human cells and permeabilized fibers from small biopsies of human muscle. Methods Mol Biol 810, $25-58$.

32. Ramos-Filho D, Chicaybam G, de-Souza-Ferreira E, et al. (2015) High intensity interval training (HIIT) induces specific changes in respiration and electron leakage in the mitochondria of different rat skeletal muscles. PLOS ONE 10, e0131766.

33. Teodoro JS, Palmeira CM \& Rolo AP (2015) Determination of oxidative phosphorylation complexes activities. Methods $\mathrm{Mol}$ Biol 1241, 71-84.

34. Starkov AA (2010) Measurement of mitochondrial ROS production. Methods Mol Biol 648, 245-255.

35. Santiago AP, Chaves EA, Oliveira MF, et al. (2008) Reactive oxygen species generation is modulated by mitochondrial kinases: correlation with mitochondrial antioxidant peroxidases in rat tissues. Biochimie 90, 1566-1577.

36. Wong R, Steenbergen C \& Murphy E (2012) Mitochondrial permeability transition pore and calcium handling. Methods Mol Biol 810, 235-242.

37. Machado RM, Stefano JT, Oliveira CP, et al. (2010) Intake of trans fatty acids causes nonalcoholic steatohepatitis and reduces adipose tissue fat content. J Nutr 140, 1127-1132.

38. Burgueno AL, Cabrerizo R, Gonzales Mansilla N, et al. (2013) Maternal high-fat intake during pregnancy programs metabolic-syndrome-related phenotypes through liver mitochondrial DNA copy number and transcriptional activity of liver PPARGC1A. J Nutr Biochem 24, 6-13.

39. Fu S, Watkins SM \& Hotamisligil GS (2012) The role of endoplasmic reticulum in hepatic lipid homeostasis and stress signaling. Cell Metab 15, 623-634.

40. Rutter GA \& Pinton P (2014) Mitochondria-associated endoplasmic reticulum membranes in insulin signaling. Diabetes 63, 3163-3165.

41. Zhang Q, Tamura Y, Roy M, et al. (2014) Biosynthesis and roles of phospholipids in mitochondrial fusion, division and mitophagy. Cell Mol Life Sci 71, 3767-3778.

42. Genova ML \& Lenaz G (2014) Functional role of mitochondrial respiratory supercomplexes. Biochim Biophys Acta 1837, 427-443.

43. Nathan C \& Cunningham-Bussel A (2013) Beyond oxidative stress: an immunologist's guide to reactive oxygen species. Nat Rev Immunol 13, 349-361.

44. Zorov DB, Juhaszova M \& Sollott SJ (2014) Mitochondrial reactive oxygen species (ROS) and ROS-induced ROS release. Physiol Rev 94, 909-950.

45. Arruda AP, Pers BM, Parlakgul G, et al. (2014) Chronic enrichment of hepatic endoplasmic reticulum-mitochondria contact leads to mitochondrial dysfunction in obesity. Nat Med 20, 1427-1435.

46. Lynes EM, Raturi A, Shenkman M, et al. (2013) Palmitoylation is the switch that assigns calnexin to quality control or ER Ca2+ signaling. J Cell Sci 126, 3893-3903.

47. Khairallah RJ, Kim J, O'Shea KM, et al. (2012) Improved mitochondrial function with diet-induced increase in either docosahexaenoic acid or arachidonic acid in membrane phospholipids. PLOS ONE 7, e34402.

48. Fouret G, Tolika E, Lecomte J, et al. (2015) The mitochondrialtargeted antioxidant, MitoQ, increases liver mitochondrial cardiolipin content in obesogenic diet-fed rats. Biochim Biophys Acta 1847, 1025-1035.

49. Hoile SP, Irvine NA, Kelsall CJ, et al. (2013) Maternal fat intake in rats alters 20:4n-6 and 22:6n-3 status and the epigenetic regulation of Fads2 in offspring liver. $J$ Nutr Biochem 24, $1213-1220$. 